\title{
Experimental Study on Conducted EMI Mitigation in SMPS using a Novel Spread Spectrum Technique
}

\author{
L. Premalatha ${ }^{\dagger}$, T. A. Raghavendiran ${ }^{*}$, and C. Ravichandran * \\ $\dagger^{*}$ Dept. of Electrical and Electronic Engineering, Anand Institute of Higher Technology, Chennai, India
}

\begin{abstract}
Switched mode power supplies (SMPS) are power electronic circuits extensively used in a wide range of applications. High frequency switching operation of SMPS causes electromagnetic emissions and has the potential to interfere with system operation, which in turn has an impact on system performance. This makes electromagnetic compatibility (EMC) an important concern. In this paper, a new and simple spread spectrum technique is proposed by modulating chaotic pulse position modulation (CPPM) and pulse width modulation (PWM). The resulting CPWM is implemented to reduce the conducted EMI in SMPS. The proposed method is found to be effective in reducing conduction EMI. The effectiveness and simplicity of the proposed method on spreading those dominating frequencies is compared to the EMI mitigation technique using an external chaotic generator. Finally, the levels of conductive EMI with standard PWM, CPWM with an external chaos generator and the proposed method are experimentally verified to comply with the CISPR 22A regulations. The results confirm the effectiveness of the proposed method.
\end{abstract}

Key words: Chaotic pulse position modulation, Chaotic pulse width modulation, EMC, EMI, External chaos generator, SMPS

\section{INTRODUCTION}

Switched mode power supplies (SMPS) are widely used in various sectors such as communications, control and military applications. In terms of electromagnetic interference (EMI), SMPS have always been a serious concern due to their unwanted radiations. The increased switching frequency, together with the increased current and voltage slew rates, $\mathrm{di} / \mathrm{dt}$ and $\mathrm{dv} / \mathrm{dt}$, have detrimental effects on the electromagnetic compatibility (EMC) performance of these power supplies. Commercial power supplies cannot be put on the market until certain EMC regulations are met. In addition, SMPS must provide the desired electrical functionality, in order to meet the international standards of electromagnetic compatibility (EMC) by reducing conducted and radiated emissions [1].

The dc-dc conversion in switched mode converters is based on the pulse width modulation (PWM) technique. Under the steady state operation of SMPS, the constant switching frequency results in undesirable harmonics at multiples of the switching frequency in the power spectrum of the output

Manuscript received Sep. 4, 2012; revised Apr. 19, 2013

Recommended for publication by Associate Editor Bor-Ren Lin.

†Corresponding Author: premaprak@yahoo.com

Tel: +91-44-2449-2031, Anand Institute of Higher Technology

*Dept. of Electrical \& Electronics Eng., Anand Institute of Higher

Technology,India signal. These undesirable noises are often associated with conducted electromagnetic interference emissions [2]. There are several methods available in the literature for reducing EMI such as filter methods, soft switching methods, random modulation methods, chaotic modulation methods, etc [3]-[8]. With the random switching scheme, the harmonic power concentration in the frequency domain is reduced and the peak level of the power spectral density (PSD) becomes less than that of classical PWM. The discrete harmonics are significantly reduced and the harmonic power is spread over a continuous noise spectrum of insignificant magnitude [9].

On the other hand, operating a system in chaos, where the ripple waveform becomes aperiodic, has the effect of spectral spreading without any additional circuitry which can be effectively used in countering the EMI problem [10]. Two popular methods have been suggested in the literature to achieve the suppression of EMI by chaos technology [11]. The first method is the parameter-controlling method [12]-[15]. The switching converters are operated under the chaos state by controlling the various parameters of the system. The problem with this method is that it is difficult to achieve a satisfying design. The second method is the variable frequency modulation method [16]. It mainly utilizes the broadband nature of the clock signals generated by the chaotic system to reduce EMI. Some methods for spreading the spectrum through chaotic modulation have been proposed 


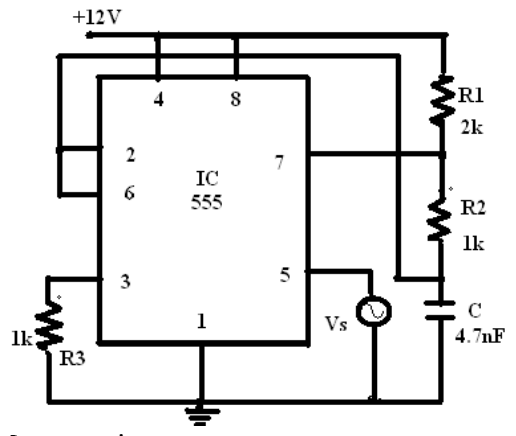

Fig. 1. CPPM generation.

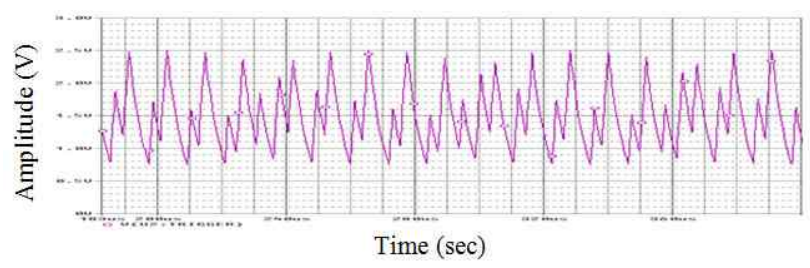

(a) Capacitor output voltage signal.

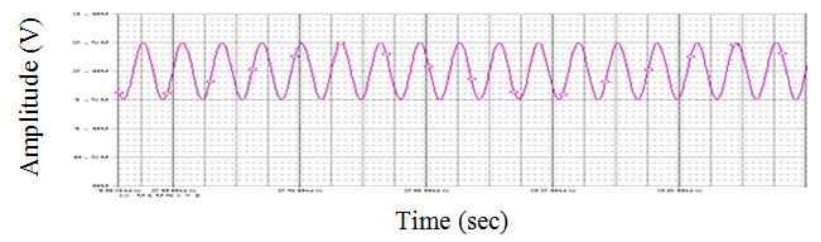

(b) Modulation signal.

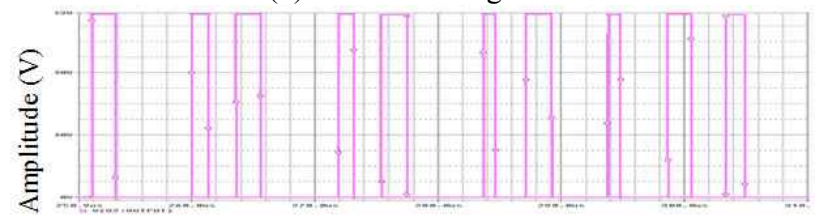

Time (sec)

(c) Chaotic PPM.

Fig. 2. Generated chaotic $\mathrm{PPM}$ for $\mathrm{C}=0.0047 \mu \mathrm{F}$.

\section{in [17]-[21].}

Chua's circuit has been implemented as a chaos generator in [22], [23]. In these methods, chaos is incorporated into the circuit with an external chaos generator circuit. However, [24] reported some inherent shortcomings of chaos like reduced efficiency due to an increased ripple and a higher emission floor. A common limitation of all these methods is that once a converter has been designed for a particular EMC norm, it cannot be tuned to satisfy some other norm or have to be overdesigned [25]. Similar methods for spreading the spectrum through chaotic modulation have been proposed in [26], [27] but they use DSP boards to obtain chaotic waveforms through software programming.

This paper introduces a novel and easy approach for reducing the electromagnetic interference in SMPS using chaos, based on the approaches of [28]-[31]. In the proposed scheme, the converter is designed to work in a regular periodic regime, with a low ripple. The feedback PWM is then modulated with chaotic PPM (CPPM) produced by a
555 timer. This generates chaotic PWM that makes the converter switching chaotic, which results in spectrum spreading and a consequent reduction of the spectral peaks.

\section{ChaOtic Pulse Position Modulation}

Pulse position modulation (PPM) is a pulse modulation technique that uses pulses of uniform height and width but displaced in time from some base position according to the amplitude of the signal at the instant of sampling. In this study, an LM555 timer has been used to generate CPPM. The timer is connected for stable operation, as shown in Fig.1, with the modulating signal $\mathrm{V}_{\mathrm{s}}$ applied to the control voltage terminal. The signal $\mathrm{V}_{\mathrm{s}}$ is a sinusoidal voltage generated by a sinusoidal voltage generator. The pulse position varies with the modulating signal since the threshold voltage and hence the time delay is varied.

The capacitor value has been calculated as follows:

$$
C=1.44 /\left(R_{1}+R_{2}\right) f_{o}
$$

where $f_{o}$ is the frequency of the oscillation. It has been found experimentally that when $f_{o}$ is less than the frequency of the modulating signal, the output of the LM555 timer is a standard PPM signal. However, when $f_{o}$ is equal to or greater than the frequency of the modulating signal, the PPM becomes chaotic. Hence by varying the capacitor value, a chaotic PPM is obtained. Here $\mathrm{C}=0.0047 \mu \mathrm{F}$ was chosen for generating the chaotic PPM.

Fig. 2 shows the waveforms generated for a sinusoidal wave modulation signal.

\section{FORWARD CONVERTER}

Forward converters are a popular SMPS used for producing isolated and controlled dc voltages from an unregulated dc supply.

\section{A. Forward Converter with the Standard PWM Technique}

Fig. 3 shows the block diagram of a voltage-mode controlled forward converter. In this circuit, the switch is controlled by load voltage feedback. In operation, the differential amplifier compares the voltage across the load resistor with the reference voltage. The output of this amplifier is compared with the ramp voltage (carrier), resulting in PWM pulses that determine the state of the switching action of the converter.

\section{B. Forward Converter with CPWM Generated by An External Chaos Generator}

Figure 4 shows a block diagram of a forward converter with an external chaotic generator added to it. The generator circuit chosen is Chua's oscillator [32]. 


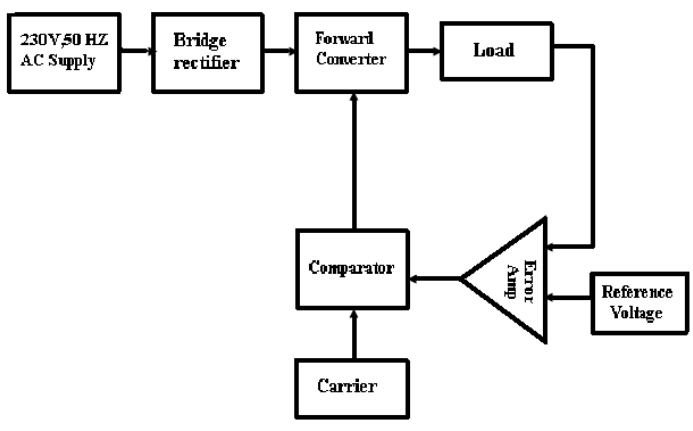

Fig. 3. Forward converter with conventional PWM technique.

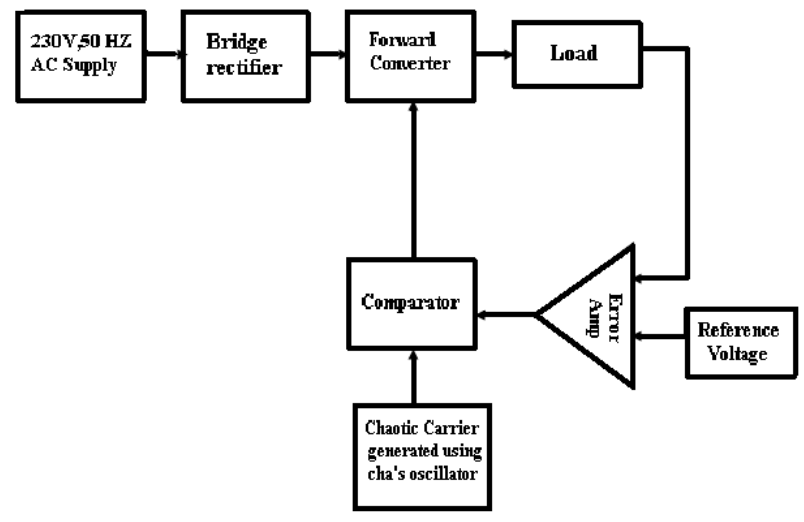

Fig. 4. Forward converter with CPWM generated by external chaotic generator.

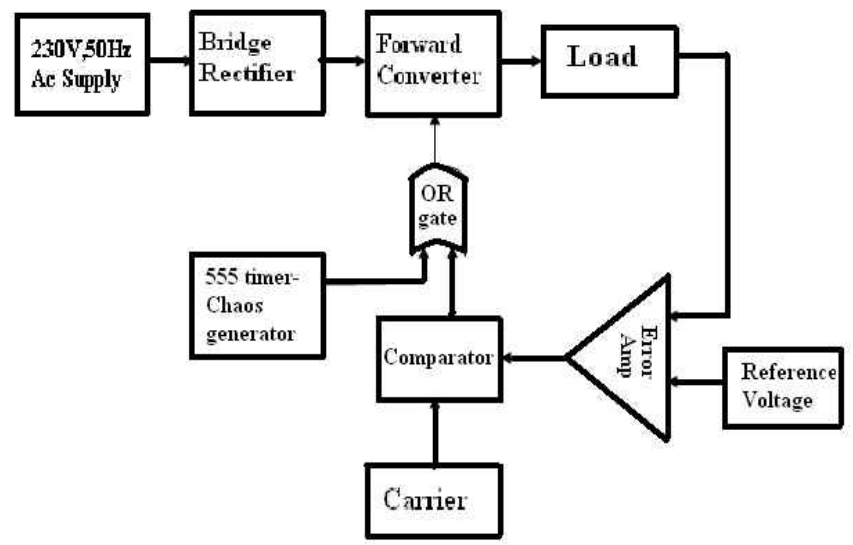

Fig. 5. Forward converter with proposed technique.

\section{Forward Converter with CPWM Generated by the Proposed Method}

To generate chaotic PWM for EMI reduction with the proposed method, a 555 timer and an OR gate are included in the conventional forward converter, as shown in Fig.5.

The output of the comparator is a PWM signal. This signal together with the chaotic PPM signal produced by the 555 timer are given as inputs to the OR gate. The output of the OR gate is a chaotic PWM pulse. This pulse in turn operates the converter chaotically. The PWM output of the comparator,

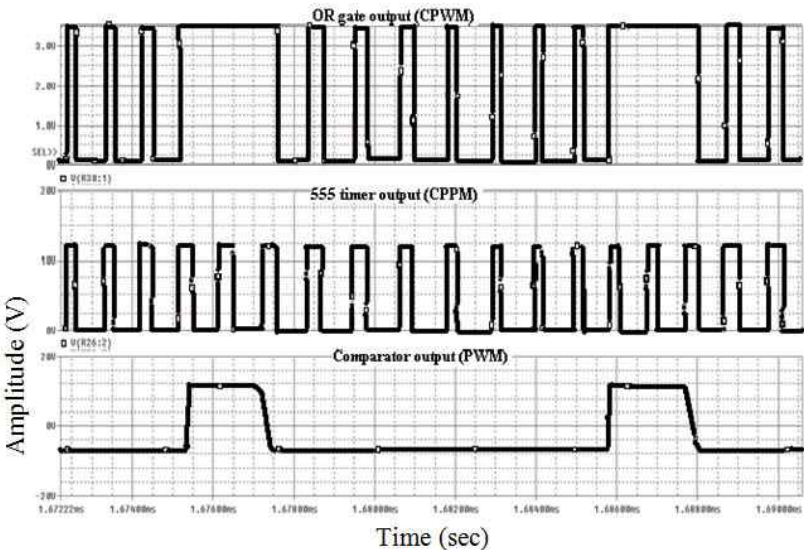

Fig. 6. Generation of chaotic PWM pulses.

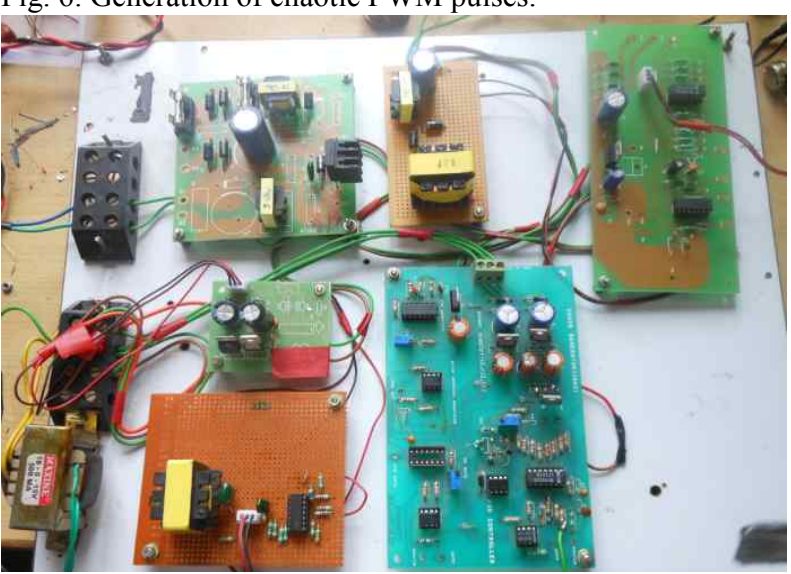

Fig. 7. Experimental prototype of forward converter with external chaos generator circuit.

the PPM output of the 555 timer and the chaotic PWM output of the OR gate are shown in Fig.6.

\section{MEASURED RESULTS - EMI REDUCTION IN SMPS}

A forward converter has been designed, built and tested for chaos and EMI reduction. The power of the converter is $65 \mathrm{~W}$, the input ac voltage is $220 \mathrm{~V} 50 \mathrm{~Hz}$, the rectified dc input is $160 \mathrm{~V}$, the dc output is $19.5 \mathrm{~V} 3.5 \mathrm{~A}$ and the switching frequency is $100 \mathrm{kHz}$. The converter is designed to operate periodically under various system parameter disturbances. It has been found that the converter output is constantly periodic when the input voltage is varied from $140 \mathrm{~V}$ to 180 V.

Fig. 7 shows an experTime (sec) stotype of a forward converter embedded with an external chaos generator. The converter is found to operate chaotically for an input voltage in the range of $140 \mathrm{~V}$ to $180 \mathrm{~V}$.

Fig. 8 shows an experimental prototype of the forward converter with the implementation of the proposed CPWM method. With the proposed method for generating and applying chaotic PWM to the switch, the converter is found to operate chaotically for an input voltage in the range of 140 $\mathrm{V}$ to $180 \mathrm{~V}$. 


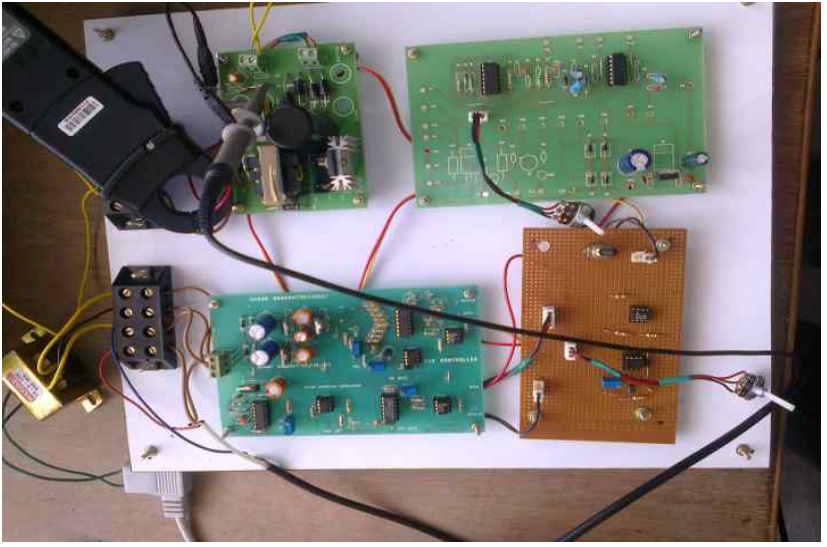

Fig. 8. Experimental prototype of forward converter with proposed CPWM.

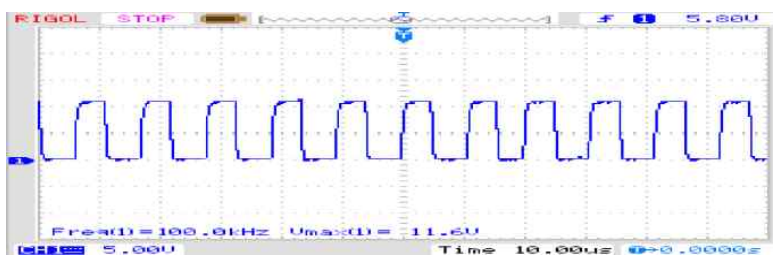

(a) Gate pulse waveform.

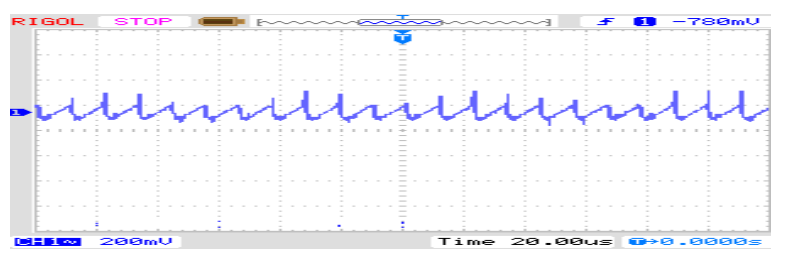

(b) Capacitor voltage waveform.

Fig 9. Measured waveforms (Periodic for both $V_{\text {in }}=140 \mathrm{~V}$ and $\mathrm{V}_{\text {in }}=180 \mathrm{~V}$ ) with PWM modulation.

\section{A. Converter with PWM Modulation - Measured Results}

The measured waveforms for the forward converter with the standard PWM method are obtained and the results are shown in Fig.9.

It has been found that the gate pulses and the output voltage are periodic over an input voltage in the range of $140 \mathrm{~V}$ and $180 \mathrm{~V}$.

\section{B. Converter with CPWM generated by an External Chaos Generator Circuit - Measured Results}

The measured waveforms for the forward converter with the addition of an external chaotic generator circuit are shown in Fig. 10.

The gate pulses and the output voltage are chaotic over an input voltage in the range of $140 \mathrm{~V}$ and $180 \mathrm{~V}$, with the CPWM generated by the external chaos generator, as shown in Fig. 10.

C. Converter with the Proposed Simple CPWM Generation Technique - Measured Results

Similarly, the measured waveforms for the forward

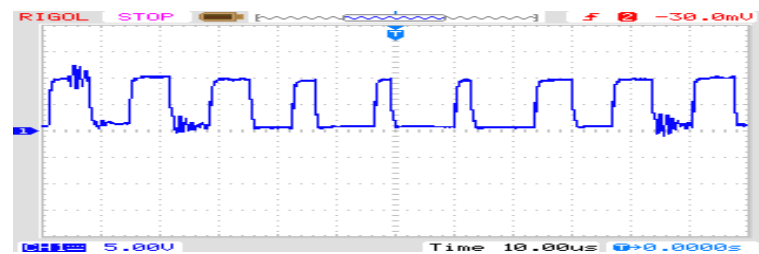

(a) Gate pulse waveform.

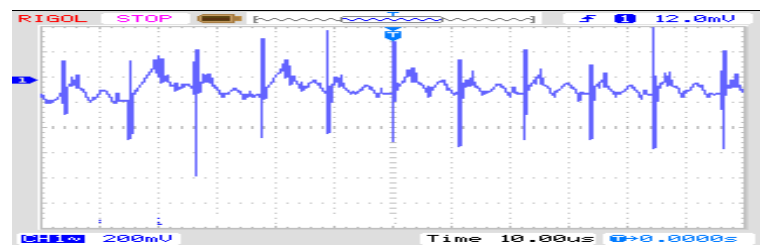

(b) Capacitor voltage waveform.

Fig. 10. Measured waveform (chaotic for both $V_{\text {in }}=140 \mathrm{~V}$ and $\mathrm{V}_{\text {in }}=180 \mathrm{~V}$ ) with CPWM generated by external chaos generator.

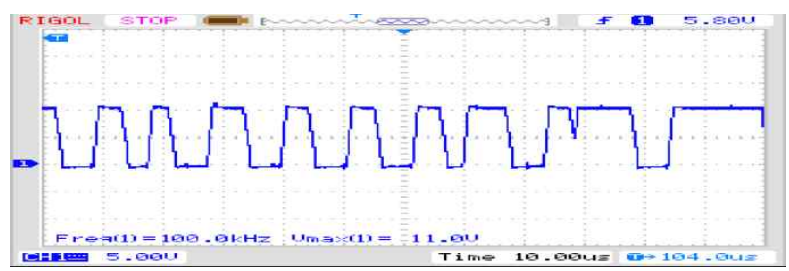

(a) Gate pulse waveform

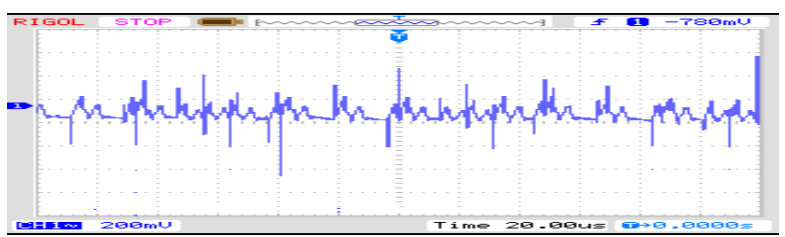

(b) Capacitor voltage waveform.

Fig 11. Measured capacitor voltage waveform (chaotic for both $\mathrm{V}_{\text {in }}=140 \mathrm{~V}$ and $\mathrm{V}_{\text {in }}=180 \mathrm{~V}$ ) with CPWM generated by proposed method.

converter with the proposed simplified CPWM method are obtained and the results are as shown in Fig.11.

It can be seen in Fig.11, that the gate pulses and the output voltage are chaotic over an input voltage in the range of 140 $\mathrm{V}$ and $180 \mathrm{~V}$, with the proposed method.

The power density spectrums of the output voltage under periodic operation of the converter with the standard PWM, the spectrum under chaotic operation of the converter (by parameter modulation) with the standard PWM and the spectrum under chaotic operation with the external chaos generator are compared in Fig.12 and Fig.13, respectively.

In Fig.12, the periodic spectrum under PWM is compared with the chaotic spectrum under PWM. The chaotic spectrum in Fig.12 is obtained by operating the converter in chaos, while varying the load resistance. It can be seen in Fig. 12 that, the height of the peaks is reduced to a considerable extent, when the converter is operated in the chaotic state rather than the periodic state. The power is densely concentrated at the fundamental frequency of $100 \mathrm{kHz}$ and its harmonics during periodic operation whereas the spectrum is continuous and 


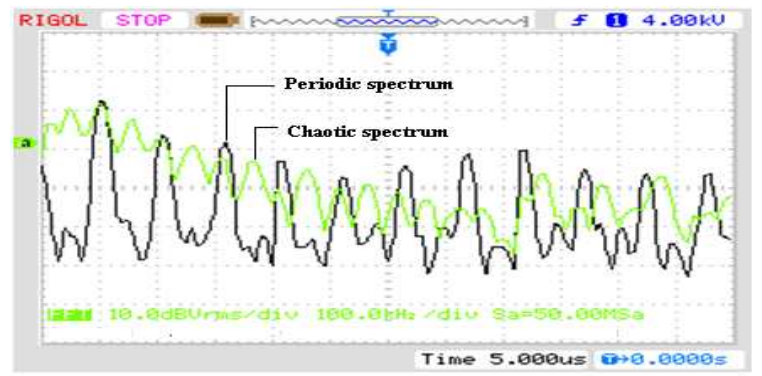

Fig. 12. Comparison of periodic and chaotic spectrums under PWM modulation.

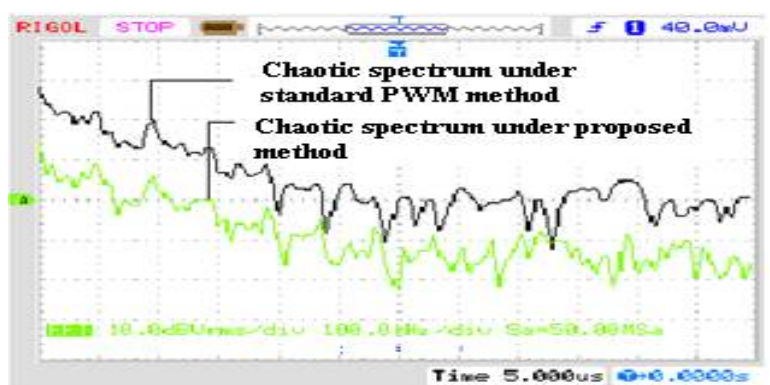

Fig. 13. Comparison of chaotic spectrum(with parameter modulation) under PWM and chaotic spectrum under CPWM generated by the proposed method.

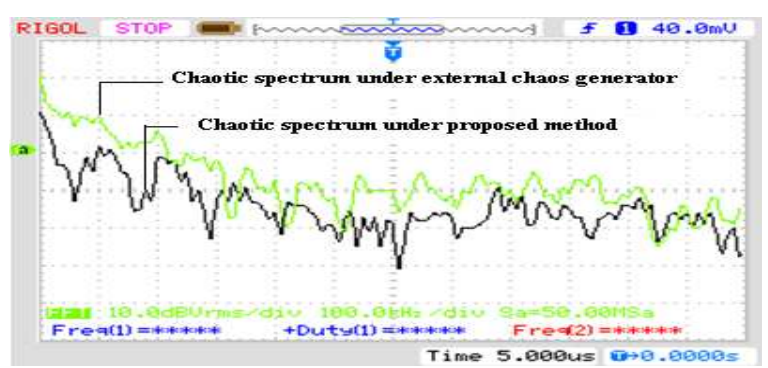

Fig. 14. Comparison of chaotic spectrum with external chaotic generator and chaotic spectrum with proposed method.

the amplitudes of the spectral peaks are reduced during chaotic operation. This is because the total emitted energy is spread over a wider frequency range thereby reducing the peak emissions. The plot shows that operating the system in chaotic mode is effective at lowering the peak levels of both fundamental and harmonic peaks.

Fig. 13 shows the comparison of the FFTs between the chaotic operation of the converter under the standard PWM method and the periodic and the chaotic operation of the converter with the proposed simplified CPWM method. It is found that the emission level for the proposed method is comparatively lower than that of the converter operating in chaos under the standard PWM method.

In addition, as seen in Fig.14, the level of the emission peaks with the proposed simple CPWM method is found to be comparatively lower than that of the peak emissions with the external chaos generator.

Hence it is experimentally verified from the spectral analysis that the proposed CPWM effectively suppresses the peaky EMI.

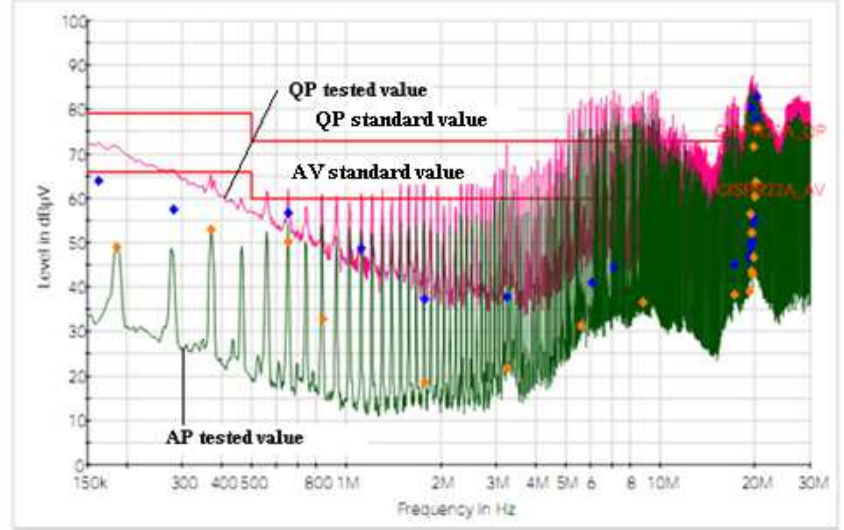

Fig. 15. Conduction EMI test results under standard PWM method.

\section{EMI TEST ANALYSIS}

The conducted EMI measurements are carried out with a $150 \mathrm{kHz}$ to $30 \mathrm{MHz}$ line impedance stabilization network (LISN) and an EMI analyzer. The EMI test criterion is CISPR 22A. Practical measurements of the conducted EMI of a $65 \mathrm{~W}$ dc-dc forward converter are given in Fig.15, Fig. 16 and Fig.17, respectively. The top standard line is the quasi-peak (QP) value limit and the bottom standard line is the average value (AV) limit. QP is used to quantify the annoyance factor of the signal by weighing its repetition rate in addition to its frequency and amplitude. It is measured by placing the signal in the EMI receiver and performing a remeasure using the detector.

The converter qualifies if the measured quasi-peak values are below the quasi-peak limit and the average limit, and the average values are below the average limit.

As seen in Fig.15, under the conventional PWM method, the noise energy exceeds the QP and AV limits after the $5 \mathrm{M}$ frequency point. The EMI test of the SMPS is disqualified under the constant PWM scheme.

In Fig.16, it can be seen that the noise energy gets reduced to below the QP and AV limits with the application of the external chaotic generator.

Under the proposed CPWM method, as shown in Fig.17, the noise energy is spread over a wide frequency range, and the peaky emissions are found to be a lot less when compared with Fig. 15 and Fig.16. The QP and AV tested values are all within their limits, and the SMPS is found to be qualified. A reduction of more than $20 \mathrm{~dB}$ is noticed in the envelope of the spectrum. This demonstrates the effectiveness of using the proposed CPWM scheme in suppressing the EMI of the SMPS.

\section{CONCLUSION}

A novel and simple method of CPWM generation and its implementation to SMPS for EMI reduction, is discussed in this paper. The method is compared with the CPWM 


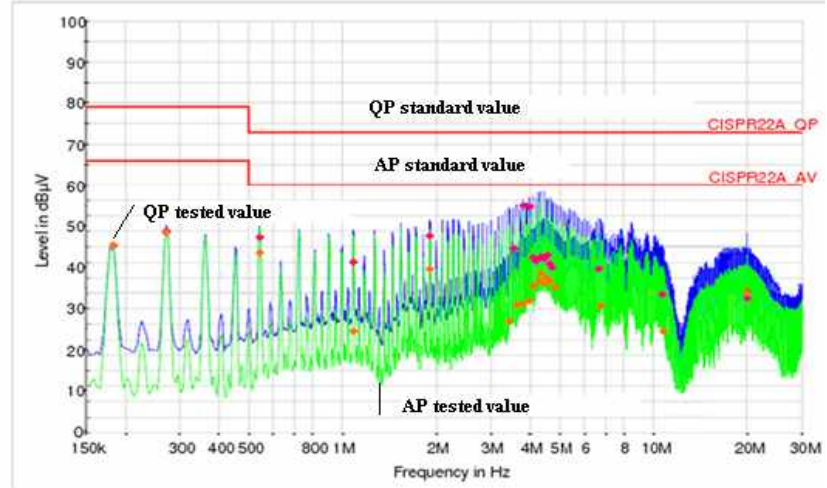

Fig. 16. Conduction EMI test results with external chaotic generator circuit.

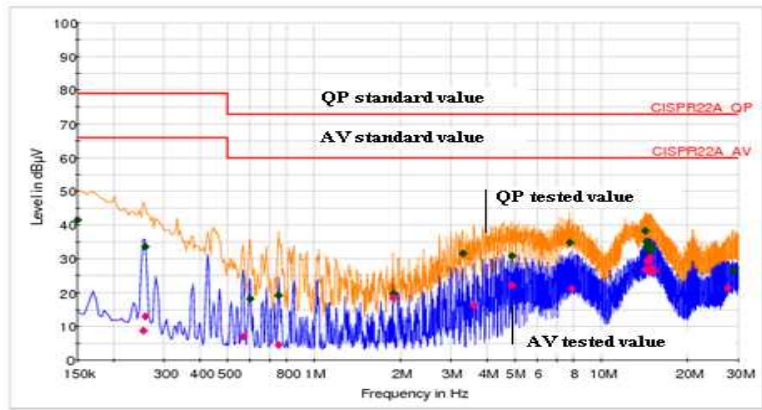

Fig. 17. Conduction EMI test results under the proposed method.

generated by an external chaos generator and it is found to have advantages like low cost, compactness and ease of design. The peaky emissions are found to be comparatively less with this approach. Measured results validate the suitability of the proposed method. Finally, the levels of conductive EMI for the SMPS are experimentally verified to comply with the CISPR $22 \mathrm{~A}$ regulations and the results confirm the effectiveness of the proposed method.

\section{APPENDIX}

SMPS design specifications

Input voltage ( $\mathrm{min})$

$140 \mathrm{~V}$ DC

nput voltage (max)

$180 \mathrm{~V}$ DC

Input voltage(nominal) $\quad \mathrm{V}_{\text {in }}$ $160 \mathrm{~V} \mathrm{DC}$

Output voltage $\mathrm{V}_{\mathrm{o}}$

19.5 V DC

Output current $\mathrm{I}_{\mathrm{o}}$

Max output voltage ripple

$0.195 \mathrm{~V}$

$\left(1 \%\right.$ of $\left.\mathrm{V}_{\mathrm{o}}\right)$

Max output current ripple

$\left(20 \%\right.$ of $\left.\mathrm{I}_{\mathrm{o}}\right)$

Output power $\mathrm{P}_{\mathrm{o}}$

$68.25 \mathrm{~W}$

Peak input current

$1.42 \mathrm{~A}$

Output resistance $\mathrm{R}_{\mathrm{L}}$
Switching frequency
Input current
Max. duty ratio $\mathrm{D}_{\max }$
Max.flux density
Change in flux density
Max.current density
Winding factor due to isolation
Winding factor between primary
and secondary

$5.6 \Omega$

$100 \mathrm{kHz}$

$450 \mathrm{~A} / \mathrm{cm}^{2}$

0.5

Inductor winding factor

\section{ACKNOWLEDGEMENT}

This work was supported in part by DRDO under grant of ER \& IPR.

\section{REFERENCES}

[1] G. A. Covic and J. T. Boys, "Noise quiting with random PWM AC drives," IEE Proc. Electr. Power. Applications, Vol. 145, No. 1, pp. 1-10, 1998.

[2] A. M. Stankovic, G. C. Verghese, and D. J. Perreault, "Analysis and synthesis of randomised modulation schemes for power converters," IEEE Trans. Power Electron., Vol. 10, No. 6, pp. 680-693, Nov. 1995.

[3] K. Borisov, H. L. Ginn, and A. M. Trzynadlowski, "Attenuation of electromagnetic interference in a shunt active power filter," IEEE Trans. Power Electron., Vol. 22, No. 5, pp. 1912-1918, Sep. 2007.

[4] H. Chung, S. Y. R. Hui, and K. K. Tse, "Reduction of power converter EMI emission using soft-switching technique," IEEE Trans. Electromagn. Compat., Vol. 40, No. 3, pp.282-287, Aug. 1998.

[5] A. M. Stankovic, G. C. Verghese, and D. J. Perreault, "Analysis and synthesis of randomized modulation schemes for power converters," IEEE Trans. Power Electron., Vol. 10, No. 6, pp. 680-693, Nov. 1995.

[6] K. K. Tse, R. W. M. Ng, H. S. H. Chung, and S. Y. R. Hui, "An evaluation of the spectral characteristics of switching converters with chaotic carrier-frequency modulation," IEEE Trans. Ind. Electron., Vol. 50, pp. 171-182, Feb. 2003.

[7] K. K. Tse, H. S.-H. Chung, S. Y. R. Hui, and H. C. So, "A comparative study of carrier-frequency modulation techniques for conducted EMI suppression in PWM converters," IEEE Trans. Ind. Electron., Vol. 49, No. 3, pp. 618-627, Jun. 2002.

[8] S. Callegari, R. Rovatti, and G. Setti, "Chaotic modulations can outperform randomness in electromagnetic interference reduction tasks," Electronic Letters, Vol. 38, No. 12, pp. 543-544, 2002.

[9] J. Balcells, A. Santolaria, A. Orlandi, D. Gonzalez, and J. Gago, "EMI reduction in switched power converters using frequency modulation techniques," IEEE Trans. Electromagn. Compat., Vol. 47, No. 3, pp. 569-576, Aug. 2005. 
[10] K. K. Tse, H. S. Chung, S. Y. R. Hui, and H. C. So, "A comparative investigation on the use of random modulation schemes for DC/DC converters," IEEE Trans. Ind. Electron., Vol. 47, No. 2, pp.253-263, Apr. 2000.

[11] J. H. B. Deane and D. C. Hamill, "Improvement of power supply EMC by chaos," Electronic Letters, Vol. 32, No. 12, p. $1045,1996$.

[12] F.-C. Chen and P.-N. Shen, "Suppression of Electromagnetic Interference of DC-DC Power Converters by Chaos Generators," Universitites Power Engineering Conference, pp.1-6, 2010.

[13] D. C. Hamill, J. H. B. Deane, and P. J. Aston, "Some applications of chaos in power converters," Update on New Power Electronic Techniques (Digest No: 1997/091), IEE Colloquium, pp. 5/1-5/5,1997.

[14] S. Banerjee, D. Kastha, and S. SenGupta, "Minimising EMI problems with chaos," Proceedings of Electromagnetic Interference and Compatibility, pp. 162-167, 2002.

[15] R. S. Bueno and J. L. R. Marrero, "Control of DC-DC converters in the chaotic regime," Proceedings of Control Applications, Vol. 2,pp. 832-837,1998.

[16] A. L. Baranovski, A. Mogel, W. Schwarz, and O. A. W. O. Woywode, "Chaotic control of a DC-DC-converter," Proceedings of Circuits and Systems, pp. 108-111, 2000 .

[17] M. Kuisma and P. Silventoinen, "Analyzing current ripple in variable-frequency boost converter," Power Electronics Specialists Conference, pp. 1535-1540, 2007.

[18] S. Callegari, R. Rovatti, and G. Setti, "Chaos-based FM signals: application and implementation issues," IEEE Trans. Circuits Syst. I, Fundam. Theory Appl., Vol. 50, pp. 1141-1147, Aug. 2003.

[19] G. Setti, R. Rovatti, S. Callegari, and M. Balestra, "Control of chaos statistics for the generation of timing signals with improved EMC," Chaos and Bifurcation Control: Theoryand Applications - Part I: Chaos Control.

[20] S. Callegari, R. Rovatti, and G. Setti, "Chaos based Improvement of EMI Compliance in Switching Loudspeaker Drivers," European Conference on Circuit Theory and Design, 2001.

[21] M. Balestra, A. Bellini, S. Callegari, R. Rovatti, and G. Setti, "Chaos-based generation of PWM-like signals for low-EMI induction motor drives: analysis and experimental results," IEICE Trans. Electronics, Vol. 87, pp. 66-75, 2004.

[22] K. K. Tse, R. W. M. Ng, H. S. H. Chung, and S. Y. R. Hui, "An evaluation of the spectral characteristics of switching converters with chaotic carrier-frequency modulation," IEEE Trans. Ind. Electron., Vol. 50, pp. 171-182, Feb. 2003.

[23] O. G. Saracoglu and R. Kilic, "A simulation study on EMI effects in autonomous Chua's chaotic circuit," IEEE Symp. Electromagnetic Compatibility, Vol. 1, pp. 280-283, 2003.

[24] S. Banerjee, A. L. Baranovski, J. L. R. Marrero, and O. Woywode, "Minimizing electromagnetic interference problems with chaos," IEICE Trans. Fundamentals, Vol. E87-A, No. 8, pp. 2100, 2004.

[25] R. M. A. Patra and S. Banerjee, "A chaos-modulated ramp generator IC for flexible EMI reduction in voltage-mode controlled PWM buck converters," IEEE proc. Integrated Circuits , pp. 410-413, 2007.

[26] G. Setti, R. Rovatti, S. Callegari, and M. Balestra, "Control of chaos statistics for the generation of timing signals with improved EMC," Chaos and Bifurcation Control: Theory and Applications, pp. 341-369, 2003.

[27] M. Balestra, A. Bellini, C. Callegari, R. Rovatti, and G. Setti, "Chaos- based generation of PWM-like signals for
low-EMI induction motor drives: Analysis and experimental results," IEICE Trans. Fundamentals, Vol. 87-A, pp. 66-75, 2004.

[28] R. Mukherjee, S. Nandi, and S. Banerjee, "Reduction in spectral peaks of DC-DC converters using chaos-modulated clock," IEEE conference proceedings, pp.3367-3370, 2005.

[29] K. K. Tse, R.-M. Ng, H. S.-H. Chung, and S. Y. Ron Hui, "An evaluation of the spectral characteristics of switching converters with chaotic carrier-frequency modulation," IEEE trans. Ind. Electron., Vol. 50, No. 1, pp.171-182, Feb. 2003.

[30] R. Mukherjee, A. Patra, and S. Banerjee, "Chaos-modulated ramp IC for EMI reduction in PWM buck convertersdesign and analysis of critical issues," IEEE conf. on VLSI design, pp. 305-310, 2008.

[31] B. Chuang, W. Jingmei, J. Kelin, W. Chang, "EMI reduction by chaos in the forward converter," Int. conf on electronic measurements and instrumentation, pp. 4.774.80, 2007.

[32] H. Li, Z. Li, B. zhang, F. W. Tan, and W. A. Halang, "Design of analogue chaotic PWM for EMI suppression," IEEE Trans. Electromagn. Compat., Vol. 52, No. 4, pp. 1001-1007, Nov. 2010.

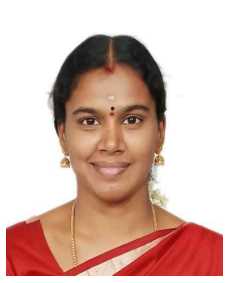

L. Premalatha received her Ph.D in Electrical Engineering from Anna University, Chennai, India. She is currently working as Professor in Anand Institute of Higher Technology, Chennai, India. Her current research interests include power electronics and drives, nonlinear dynamic systems and control, electromagnetic compatibility and power quality.

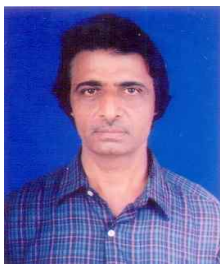

T. A. Raghavendiran obtained his Ph.D from Anna University, Chennai, India, in 2004. He is currently, serving as Principal in Anand Institute of Higher Technology, Chennai, India. His current research interests include power electronics, energy systems and power quality.

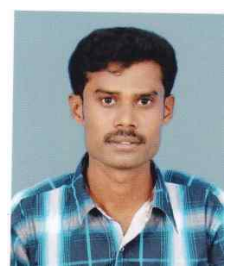

C. Ravichandran obtained his M.S. in Engineering at the Thiagarajar College of Engineering, Madurai, India. He is currently pursuing his $\mathrm{Ph} . \mathrm{D}$ at Anna University, Chennai, India. $\mathrm{He}$ is also working as Assistant Professor in Anand Institute of Higher Technology, Chennai, India. His current research interests include power quality and grid integrated renewable energy systems. 